Revista de Investigación Educativa 24

enero-junio, 2017 | ISSN 1870-5308 | Xalapa, Veracruz

Instituto de Investigaciones en Educación | Universidad Veracruzana

\title{
Algunas consideraciones teóricas sobre la enseñanza- aprendizaje de la traducción e interpretación en el contexto universitario
}

\author{
Dr. Emilio Ortega Arjonilla \\ Departamento de Traducción e Interpretación \\ Universidad de Málaga, España \\ eortega@uma.es
}

$\mathrm{N}^{\circ}$ o resulta fácil conceptualizar lo que entendemos por traducción, sobre todo teniendo en cuenta la evolución espectacular que han experimentado tanto los estudios de traducción e interpretación como la propia práctica de la traducción e interpretación desde mediados del pasado siglo xx hasta nuestros días.

Si en 1941 asistimos a la creación del primer centro universitario contemporáneo dedicado a la formación de traductores e intérpretes en la ciudad de Ginebra (ETI de Ginebra, Suiza), algunos años más tarde (1945) presenciamos la creación y utilización de las primeras cabinas de interpretación, lo que permitió la puesta en marcha de la modalidad de interpretación simultánea con motivo de la celebración de los juicios de Núremberg en la ciudad alemana del mismo nombre.

Desde entonces, gracias a la creación de organismos internacionales con varias lenguas oficiales (entidades y organismos de la ONU y entidades de la Unión Europea, entre otros) y a la internacionalización creciente de todos los ámbitos del saber y de los sectores productivos, hemos asistido a un crecimiento y una diversificación sin precedentes en la historia de la humanidad en lo que al uso de la traducción e interpretación se refiere. Lo que se ha visto reflejado en la multiplicación de centros universitarios de formación de traductores e intérpretes en todo el planeta, en los que se forma instruye a esos profesionales de la mediación lingüística y cultural que hacen posible el milagro de la comunicación a escala internacional. 
Este crecimiento exponencial de la práctica traslativa plantea, sin embargo, toda una serie de problemas a la reflexión teórica en torno a eso que llamamos traducción o interpretación, como veremos a continuación.

El primer problema al que nos enfrentamos a la hora de conceptualizar reside en la vinculación que la traducción tiene con las lenguas y culturas en las que se reflexiona sobre ella. Es decir, no existe un discurso universal e irrefutable sobre qué es y qué no es traducción, ni sobre dónde debemos situar los límites de lo traducible o intraducible, sino que hay multiplicidad de discursos que están anclados en una determinada tradición lingüística, cultural e incluso filosófica a la que deben su forma de percibir la traducción como instrumento del intercambio de información a escala internacional.

El segundo problema al que nos enfrentamos es el de la vulgarización que acompaña a la reflexión sobre la traducción: todo hablante de más de una lengua se siente autorizado para opinar sobre qué es y qué no es traducción. Así, hay quien confunde el conocimiento de lenguas con la traducción, la traducción pedagógica con la pedagogía de la traducción o la práctica habitual de la traducción en un contexto determinado de actuación con la Traducción, como si fuese posible tener una única forma de concebir y practicar eso que llamamos traducción.

En tercer lugar, nos encontramos con un fenómeno relativamente reciente que condiciona la reflexión en torno a la traducción: me refiero a los fenómenos que se engloban dentro de lo que llamamos GILT (Globalización/Internacionalización/Localización/Traducción). Es decir, tenemos que acotar dónde situamos la traducción y qué debemos considerar como actividades translativas y qué no, aunque estas no supongan la traducción completa de un documento sino solo su adaptación o cualquier otra transformación que suponga pasar un mensaje de una lengua A (origen) a una lengua $B$ (meta) con un objetivo preciso que tiene en cuenta a un destinatario (individual o colectivo) en la comunidad de hablantes de la lengua y cultura meta del proceso de traducción.

Como suele ocurrir con muchos términos y conceptos longevos, la traducción también nos pone por delante un reto importante dada su polisemia. Así, por un lado, la palabra o término "traducción" se utiliza en ocasiones para designar una actividad (oral o escrita), un proceso (el de traslación de contenidos y mensajes de una lengua a otra) y un producto (el resultado de esa traslación). Esto plantea algunas dificultades en la reflexión teórica o metateórica, traductológica, si se prefiere, que se concreta en los siguientes aspectos: 
En primer lugar, siguiendo a Zinaida Lvovskaya, debemos distinguir entre Teoría General de la Traducción (TGT) y Teorías Particulares de la Traducción (трт). Con la primera designamos toda aquella reflexión traductológica en la que el objeto de estudio, la traducción, se contempla desde una perspectiva teórica o metateórica sin entrar en consideraciones sobre su aplicabilidad a un determinado par de lenguas o a un contexto de actuación (sanitario, jurídico, económico, tecnológico, etc.). Con la segunda, sin embargo, nos referimos a la reflexión teórica que se centra en un ámbito determinado de aplicación o en un par de lenguas concreto (inglés-español, francésespañol, chino-español, etc.). Hay autores, como Jean-René Ladmiral que prefieren distinguir entre Filosofía de la Traducción y Teoría de la Traducción para referirse a lo que Lvovskaya considera como TGT у тPT respectivamente.

En segundo lugar, es obvio, siguiendo a Jakobson, que la traducción puede realizarse en el seno de una misma lengua y cultura (traducción intralingüística), entre dos lenguas y culturas (traducción interlingüística) o haciendo intervenir códigos lingüísticos y no lingüísticos (traducción intersemiótica). Esto da como resultado numerosas actividades profesionales que hoy en día conocemos como traducción-adaptación de obras en una misma lengua (edición actualizada, por ejemplo, de un clásico de la literatura), traducción de todo tipo de documentos de una lengua a otra, lo que afecta a todos los ámbitos del saber (ciencias, técnicas y tecnologías, derecho, política, economía, literatura, historia, filosofía y un largo etcétera) y, por último, todas aquellas prácticas de la traducción que englobamos dentro de lo que denominamos traducción audiovisual (doblaje, subtitulado, audiodescripción para ciegos, subtitulado para sordos, etcétera) o multimedia (localización de páginas web, de videojuegos, etcétera).

En tercer lugar, la revolución tecnológica a la que estamos asistiendo en las últimas décadas ha provocado que, junto a la traducción tradicional, también nos encontremos con el uso masivo de herramientas de traducción asistida por ordenador (TAO) en determinados contextos de actuación, y con el uso creciente de la traducción automática (TA), lo que supone que el traductor tradicional se convierta en posteditor, o si se prefiere, en revisor de la traducción generada por una máquina.

En cuarto lugar, no debe confundirse la traducción como actividad que se centra en textos escritos (independientemente del soporte en el que se divulguen) con la interpretación, que siempre tiene por objeto la "traducción oral" de discursos (interpretación de conferencias) o de intervenciones en distintos contextos de actuación, ya sean estos asistenciales (interpretación para los servicios públicos: ámbitos asisten- 
cial sanitario, judicial, policial o social), económico-financieros (interpretación para la actividad económico-financiera, comercial o empresarial), políticos y diplomáticos, para los medios de comunicación y un largo etcétera.

En resumen, la diversidad de actividades que hoy en día incluyen la traducción (textos escritos) y la interpretación (discursos o intervenciones orales) exige un rigor en la consideración del objeto de estudio para ajustar, tanto en la enseñanza como en la práctica profesional, el uso de las estrategias y técnicas adecuadas para la obtención de un producto de calidad, ya sea en el ejercicio de la traducción (texto traducido) o en el de la interpretación (discurso interpretado).

No se puede confundir, por tanto, entre traducción pedagógica (que no deja de ser un método para la enseñanza-aprendizaje de una lengua extranjera), pedagogía de la traducción e interpretación (que incluye los métodos y estrategias para formar a futuros traductores e intérpretes) y teoría y práctica de la traducción e interpretación, entendiendo que una cosa es la reflexión teórica, general o particular, y otra bien distinta la práctica, condicionada por diversos factores, de la traducción o de la interpretación en un contexto específico de actuación, ya sea éste biosanitario, jurídico, humanístico, político, tecnológico o económico.

Indudablemente no pretendo condensar en estas líneas todo lo que rodea a una disciplina tan amplia como la Traductología, que pretende dar cuenta, desde un punto de vista teórico, de todas esas actividades traslativas que se realizan de forma cotidiana en todo el mundo en forma de traducción (textos escritos) o interpretación (discursos o intervenciones orales). La idea era llamar la atención sobre la complejidad y diversificación crecientes que acompañan a estas actividades de mediación lingüística y cultural a escala internacional y evitar, de paso, que se hagan afirmaciones gratuitas o simplificadoras sobre un ámbito del saber, el de la Traductología, que trata de desentrañar la complejidad de los fenómenos traslativos con rigor académico, distinguiendo entre objetos de estudio teórico, aplicaciones prácticas, herramientas de apoyo a la traducción y métodos de enseñanza-aprendizaje en contexto universitario. 